\title{
GENETIC PARAMETERS OF FIRST LACTATION TRAITSOF HOLSTEIN COWS IN
} EGYPT

\author{
M.M.I. Salem and M.H. Hammoud
}

\author{
Department of Animal Production, Faculty of Agriculture, University of Alexandria, Alexandria, Egypt
}

SUMMARY

Data relevant to 732 Holstein cows raised at El-yoser private farm, $51 \mathrm{kmsouth}$ east Alexandria, between 1995 2005 were utilized to estimate the genetic parameters of first lactation total milk yield (TMY), 305-day milk yield (305-DMY), peak yield (PY), lactation period (LP), age at first calving (AFC), first service period (FSP), days open (DO) and number of services per conception (NSC). Also, the effects of season and year of calving and age at first calving on first lactation traits were studied.

The least squares analysis indicated that the overall least squares means of TMY, 305-DMY,PY,LP,AFC, FSP, $D O$ and NSC were $9776 \mathrm{~kg}, 8237 \mathrm{~kg}, 37.2 \mathrm{~kg}, 365.7$ day,27.1 month, 95.8 day, 114.0 day and 1.9 services, respectively. Season of calving had significant effect $(P<0.01)$ on $P Y, L P, A F C, D O$ and NSC, but had no significant effect on TMY, 305-DMY and FSP. Year of calving had significant influence $(P<0.01)$ on all studied traits except DO which was not significantly influenced. Age at first calving had significant effect $(P<0.01)$ on TMY and 305-DMY, but had no significant effect on PY, LP, FSP, DO and NSC.

The heritability estimates from univariate animal models were 0.219, 0.228, 0.150, and 0.093,0. 264, 0.091, 0.186and0.00001for TMY, 305-DMY, PY,LP, AFC, FSP, DO and NSC, respectively.The genetic corrletions estimated from bivariate animal modelswere positive ranging from 0.114 to 0.999, except those between 305-DMY andAFC, between PY andFSP and between FSP and DO withNSCwere negative (-0.034,-0.260,-0.761and -0.086, respectively).All correlations among all traits were highly significant except those between 305-DMY andAFC and betwen DO and NSC which were not significant.The positive genetic correlations between PY and each of 305-DMY and TMY indicate that selection for high PY will produce associated genetic improvement in both 305$D M Y$ and TMY. Phenotypic correlations among all traits were positive ranging from 0.010 to 0.998 except for that between FSP and NSC, which was negative (-0.172).Most of correlations were highly significant.

The results indicate the possibility of using program to improve first lactation performance of Holstein cows through selection.

\section{Keywords: heritability, genetic correlation, milk traits, reproduction, Holstein cows}

\section{INTRODUCTION}

The population of cows in Egypt is continuously increasing and was recently estimated to be about 4.53 million heads (FAO, 2010). They produce about 2.90 and 0.41 million metric tons of milk and meat, which form $50.53 \%$ of the total milk production (5.74 million metric tons) and $47.83 \%$ of the total meat production $(0.85$ million metric tons $)$, respectively (FAO, 2010).

In the last three decades, many private Holstein or Friesian dairy farms in Egypt were established. They are commonly found in the desert fringes of the delta governorates. Such large commercial dairy farms usually have stocks with herd size ranging from 200 to 500 lactating cows managed by experienced staff (Galal, 2007).

Although milk yield is a major trait with high economic importance for a dairy enterprise, other traits such as lactation period, age at first calving, first service period and days open directly affect the profitability of the dairy farm (Hammoud, 1997, Dematawewa and Berger, 1998 and Tozer and Heinrich, 2001).Estimation of the genetic parameters for such performance traits in dairy cows is necessary for the determination of an optimal breeding strategies (Ahmad et al., 2001; Javed et al., 2001;
Rahmanet al., 2007; Pantelicet al., 2008; Rehmanet al., 2008 ; Pantelicet al., 2011; Zinket al., 2012 and Goshu et al., 2014).

The objective of this investigation was to estimate the genetic parameters of first lactation traits namely, total milk yield, 305-days milk yield, peak yield, lactation period, age at first calving, first service period, days open and number of services per conception of Holstein cows raised in a commercial dairy herd in Egypt.

\section{MATERIALS AND METHODS Source of data:}

Data used in this investigation were collected from first lactation records of 732 locally born Holstein cows belong to El-yoser private farm, $51 \mathrm{kmsouth}$ east of Alexandria. The records represented 73sires and 565damsand covered the period from 1995 to 2005. The first lactation traits were: total milk yield (TMY,kg), 305-day milk yield (305-DMY, kg), peak yield (PY, kg), lactation period (LP, day), age at first calving (AFC, month), first service period (FSP, day), days open (DO) and number of services per conception (NSC).

\section{Herd management:}

Animals were housed free in shaded open yards, 
grouped according to average daily milk yield and fed ad libitum on corn silage mixed with concentrate ration (TMR) all year round and supplemented with Alfa alfa if available. Feeding allowances were offered according to milk production and physiological status as recommended by NRC (1989). Water was also available at all times. Heifers were artificially inseminated for the first time when reaching $360 \mathrm{~kg}$ of weight and pregnancy was detected by rectal palpation 60 days after service. The cows were machine milked thrice a day at $06.00 \mathrm{~h}, 13.00 \mathrm{~h}$ and $18.00 \mathrm{~h}$.

\section{Statistical procedures:}

Least squares of GLM procedure (SAS, 2008) were utilized to test the significance of the fixed effects of season of calving (4 seasons), year of calving (11years) and age at first calving (3 classes). Calvings were classified by season into autumn's between September and November, winter's between December and February, spring's between March and May and summer's between June and August. The statistical model fitted was:

$$
\mathbf{Y}_{\mathrm{ijkl}}=\boldsymbol{\mu}+\mathbf{S}_{\mathrm{i}}+\mathbf{T}_{\mathbf{j}}+\mathbf{A}_{\mathrm{k}}+\mathbf{e}_{\mathrm{ijkl}} \text { where, }
$$

$\mathbf{Y}_{\mathrm{ijkl}}$ : either TMY, 305-DMY,PY, LP, AFC, FSPDO or NSC; $\boldsymbol{\mu}$ : an underlying constant specific to each trait; $\mathbf{S}_{\mathrm{i}}$ : the fixed effect of $\mathrm{i}^{\text {th }}$ season of calving; $\mathbf{T}_{\mathbf{j}}$ : the fixed effect of $\mathrm{j}^{\text {th }}$ year of calving; $\mathbf{A}_{\mathbf{k}}$ : the fixed effect of $\mathrm{k}^{\text {th }}$ age at first calving $(\mathrm{k}=1,2 \mathrm{and} 3 ; 1=\mathrm{AFC} \leq$ $26,2=26<\mathrm{AFC} \leq 30$ and $3=\mathrm{AFC}>30$ ) and $\mathbf{e}_{\mathbf{i j k} \mathbf{l}}$ : random residual assumed to be independent normally distributed with mean zero and variance $\sigma^{2}$.

Variance and covariance components and genetic parameters were estimated using the Wombat program (Meyer, 2006) fitting univariate and bivariate animal models. The assumed model was:

$$
\mathrm{y}=\mathrm{Xb}+\mathrm{Za}+\mathrm{e} \text { where, }
$$

$y:$ a vector of observations, $b$ : a vector of fixed effects with an incidence matrix $X$, a: a vector of random animal effects with incidence matrix $Z$, and e: a vector of random residual effects with mean equals zero and variance $\sigma_{\mathrm{e}}^{2}$. The vector of additive (animal) effects (a) was assumed to be $\mathrm{N} \sim\left(0, A \sigma_{a}^{2}\right)$, where $\boldsymbol{A}$ is the numerator relationship matrix among animals in the pedigree file and $\sigma^{2}$ is direct genetic variance. The vector of residual (environmental) effects (e) was assumed to be $\mathrm{N} \sim\left(0, \mathrm{I} \sigma_{\mathrm{e}}^{2}\right)$, where I being the identity matrix, and $\sigma_{\mathrm{e}}^{2}$ is the environmental variance $\operatorname{cov}(\mathrm{a}, \mathrm{c})=0$.

The genetic corrletions between traits were estimated from bivariate animal model. The assumed model was:

$$
\left[\begin{array}{l}
y_{1} \\
y_{2}
\end{array}\right]=\left[\begin{array}{cc}
X_{1} & 0 \\
0 & X_{2}
\end{array}\right]\left[\begin{array}{l}
b_{1} \\
b_{2}
\end{array}\right]+\left[\begin{array}{cc}
Z_{1} & 0 \\
0 & Z_{2}
\end{array}\right]\left[\begin{array}{l}
a_{1} \\
a_{2}
\end{array}\right]+\left[\begin{array}{l}
e_{1} \\
e_{2}
\end{array}\right]
$$

Where $y_{i}=$ vector of observations, $b_{i}=$ vector of fixed effects, $a_{i}=$ vector of random animal effects for the $i^{\text {th }}$ trait, $e_{i}=$ vector of random residual effects for the $i^{\text {th }}$ trait, and $X_{i}$ and $Z_{i}$ are incidence matrices relating records of the $i^{\text {th }}$ trait to the fixed and the random animal effects, respectively.

It is assumed that:

$$
\operatorname{var}\left[\begin{array}{l}
a_{1} \\
a_{2} \\
e_{1} \\
e_{2}
\end{array}\right]=\left[\begin{array}{cccc}
g_{11} A & g_{12} A & 0 & 0 \\
g_{21} A & g_{22} A & 0 & 0 \\
0 & 0 & r_{11} & r_{12} \\
0 & 0 & r_{21} & r_{22}
\end{array}\right]
$$

Where $g_{11}$ is the genetic variance for trait $1, g_{22}$ is the genetic variance for trait $2, \mathrm{~g}_{12}=\mathrm{g}_{21}$ is the genetic covariance between both traits, $r_{11}$ is the residual variance for trait $1, r_{22}$ is the residual variance for trait $2, r_{12}=r_{21}$ is the residual covariance between both traits.

\section{RESULTS AND DISCUSSION}

The means, standard deviation (SD) and coefficient of variation (CV\%) of the studied traits are presented in Table (1).The means of first lactation TMY, 305-DMY, PY, LP, AFC, FSP, DO and NSCwere9776, 8237and37.2 kg,365.7 days, 27.1 monthsand95.8, 114.0 days and 1.9 services, respectively. Means were lower than those of TMY and 305-DMYreported by Abou-Bakr et al.(2006) being 13172 and $10847 \mathrm{~kg}$, respectively and those being 12054 and $9038 \mathrm{~kg}$, respectively reported by Salem et al.(2006) on other commercial herds of Holstein cows in Egypt. The mean of LP (365.7 days) was shorter than that of 370 days obtained by Abou-Bakr et al. (2006) and that of 407 days obtained by Salem et al.(2006).The mean of AFC (27.1 month) was lower than that of 29.2 month reported by Salem et al. (2006). Days open of 114.0 days obtained in this study was shorter than that of 255 days found by Abou-Bakr et al.(2000) and that of 154 days obtained by Abou-Bakr et al. (2006). The mean of NSC (1.9) was lower than that reported by Abou-Bakr et al.(2000) (2.9).

Table 1. Means, standard deviation (SD) and coefficient of variation ( $\mathrm{CV} \%)$ of the studied traits

\begin{tabular}{lcccc}
\hline Traits & N & Mean & SD & CV\% \\
\hline TMY (kg) & 669 & 9776 & 2572 & 26.3 \\
305-DMY $(\mathrm{kg})$ & 732 & 8237 & 1808 & 22.0 \\
PY (kg) & 725 & 37.2 & 6.0 & 16.2 \\
LP(day) & 682 & 365.7 & 104.8 & 28.7 \\
AFC (month) & 732 & 27.1 & 2.4 & 8.8 \\
FSP (day) & 578 & 95.8 & 40.9 & 42.7 \\
DO (day) & 407 & 114.0 & 46.1 & 40.2 \\
NSC(services) & 605 & 1.90 & 1.3 & 66.7 \\
\hline
\end{tabular}

TMY: total milk yield, 305-DMY: 305-day milk yield, PY: peak yield, LP: lactation period, AFC: age at first calving, FSP: first service period, DO: days open and NSC: number of services per conception.

\section{I- Environmental effects:}

Season of calving had significant influence $(\mathrm{P}<0.01)$ on PY, LP, AFC, FSP and DO and NSC, but had no significant influence on TMY, 305-DMY and FSP (table 2). Contradictory to this, Nigm et al.(1994) indicated that season of calving had significant effect $(\mathrm{P}<0.05)$ on first lactation TMY of Friesian cows in United Arab Emirates, but had no significant effect on LP. Also, Sadek et al. (1994) 
reported that season of calving had significant effect ( $\mathrm{P}<0.01$ ) on TMY, 305-DMY, but had no significant effect on LP of Friesian cows in commercial farms in Egypt. Moreover, Hammoud (1997) reported significant effect $(\mathrm{P}<0.01)$ of season of calving on TMY and 305-DMY, but no significant effect was detected on LP, AFC and DO of Friesian cows in Egypt. In addition, significant effect $(\mathrm{P}<0.01)$ of season of calving on first lactation TMY and significant effect on LP of Holstein cows in Turkey were reported by Tekerli and Kocak (2009). Elshalmani (2011) found that season of calving had no significant influence on first lactation TMY, but had a significant one $(\mathrm{P}<0.05)$ on $\mathrm{LP}$ and significant effect $(\mathrm{P}<0.01)$ on AFC and DO of Friesian cows in Egypt. In general, the effects of season of calving could be attributed to the changes in climatic conditions and feeding regimes prevailing during different seasons.

Table 2. Effects of season and year of calving and age at first calving on the studied traits

\begin{tabular}{lcccccccc}
\hline & \multicolumn{1}{c}{ Traits } \\
\cline { 2 - 9 } \multicolumn{1}{c}{ Factors } & TMY & 305-DMY & PY & LP & AFC & FSP & DO & NSC \\
\hline Season of calving & NS & NS & $* *$ & $* *$ & $* *$ & NS & $* *$ & $* *$ \\
Year of calving & $* *$ & $* *$ & $* *$ & $* *$ & $* *$ & $* *$ & NS & $* *$ \\
Age at first calving & $* *$ & $* *$ & NS & NS & - & NS & NS & NS \\
\hline
\end{tabular}

TMY: total milk yield, 305-DMY: 305-day milk yield, PY: peak yield, LP: lactation period, AFC: age at first calving, FSP: first service period, DO: days open and NSC: number of services per conception.

NS: Not significant $(\mathrm{P}>0.05) ; *$ : significant $(\mathrm{P}<0.05)^{* *}$ : Highly significant $(\mathrm{P}<0.01)$

The effects of year of calving on all studied traits were significant $(\mathrm{P}<0.01)$ except on $\mathrm{DO}$ which was not significantly influenced (table 2). The trends depended mainly on the endogenic conditions of individual animals, feeding and management practices and year to year climate changes. Khattab and Sultan (1990) and Sadek et al. (1994) found that year of calving had significant effect $(P<0.01)$ on first lactation TMY, 305-DMY, but had no significant effect on LP of Friesian cows in Egypt. Significant effects $(\mathrm{P}<0.01)$ of year of calving on first lactation TMY and LP of Friesian cows were obtained by Nigm et al. (1994). Hammoud (1997) reported that year of calving had significant effect on TMY and 305-DMY $(\mathrm{P}<0.01)$ and significant effect on AFC ( $\mathrm{P}<0.05)$, but had no significant effect on LP and DO. Tekerli and Kocak (2009) and Elshalmani (2011) indicated that year of calving had significant influence on TMY and AFC $(\mathrm{P}<0.01)$, but had no significant influence on LP and DO.

The effects of age at first calving on all studied traits were not significant except on TMY and 305DMY which was significant $(\mathrm{P}<0.01) \quad($ table 2$)$. Khattab and Sultan (1990) found that age at first calving had significant effect on TMY and 305-DMY $(\mathrm{P}<0.01)$, but had no significant effect on LP of Friesian cows. Significant effects $(\mathrm{P}<0.01)$ of age at first calving on first lactation TMY, 305-DMYand LP of Friesian cows were reported by Abdel-Glil (1996). Hammoud (1997) reported that age at first calving had significant effect on TMY and 305-DMY $(\mathrm{P}<0.01)$, but had no significant effect on LP and DO. However, Nigm et al. (1994),Tekerli and Kocak (2009) and El-shalmani (2011) found that age at first calving had no significant effect on TMY, LP and DO.

\section{II- Genetic parameters: \\ A- Heritability $\left(h^{2}\right)$ :}

Estimates of variance components and heritability $\left(\mathrm{h}^{2}\right)$ for first lactation studied traits are found in table (3).These estimates indicate low genetic to environmental variance ratios for lactation traits and reflected differences in their response to the existing environmental conditions. The heritability estimates for reproduction traits were generally lower than those for milk traits. This is expected due to the larger environmental influences on the reproduction traits regardless of their relationship with milk yield. Low heritability estimates for DO and FSP were observed in this study but that of NSC was close to zero. Reformation of management practices in terms of adequate heat detection, utilization of relative semen and insemination technique, adoption of effort health programs and providing sufficient nutrition may play an important role to reduce the environmental variation and consequently improve heritability of the studied traits. In general, the present estimates of heritability for TMY, 305-DMY and PY were lower than those depicted by Khattab and Sultan (1990) which were0.31, 0.43 and 0.08 for TMY, 305-DMYand LP. Abdel-Glil (1996) reported heritability estimates of $0.41,0.41,0.27$ and 0.12 for TMY, 305-DMY, LP and DO. Hammoud (1997) found heritability estimates of $0.33,0.38,0.33$, 0.32 and 0.21for TMY, 305-DMY, LP, AFC and DO. Tekerliand Kocak (2009) found heritability estimates of0.27 and 0.02 for first lactation TMY and LP of Holstein cows in Turkey. El-shalmani (2011) obtained heritability estimates of $0.37,0.38,0.06$ and 0.42 for first lactation TMY, LP, AFC and DO. Heritability estimates of 0.20 and 0.03 for first lactation TMY and DO were reported by Zink et al. (2012) for Czech Holstein cows. Tiezzi et al. (2012) and Sahin et al. (2014) reported very low heritability estimates for NSC. Goshu et al. (2014) depicted heritability estimates of $0.23,0.23,0.28,0.53$ and 0.26 for first lactation TMY, 305-DMY, LP, AFC and FSP of Holstein cows in Ethiopia.

\section{B- Genetic correlation:}

Genetic correlations among studied traits are presented in table (4). The genetic corrletions were positive ranging from 0.114 to 0.999 , except those 
between 305-DMY andAFC, between PY andFSP and between FSP and DO withNSC were negative (-0.034, $0.260,-0.761$ and -0.086 , respectively). All correlations among all traits were highly significant except those between 305-DMY andAFC and betwen DO and NSC which were not significant.The genetic correlation of 0.968 and 0.488 between PY with 305-DMY and TMY would result in a correlated response when selecting for PY and consequently could produce genetic improvement in these correlated traits. However, the negative genetic correlations between 305-DMY and AFC, between PY and FSP, between NSC and FSP and between DO and NSCcould result in deleterious in the former when selection is applied on the latter. This could be interpreted as an antagonizing association between milk production and reproduction traits. So if high yielding cows are subjected to selection for total merit improvement for the traits of concern in the present study, some technical problems such as low genetic gain or negative correlated response may arise. Therefore, high milk producers may not be the first choice for total merit amelioration. Khattab and Sultan (1990) obtained genetic correlations of $0.94,0.68$ and 0.44 between TMY and 305-DMY, between TMY and LP and between 305-DMYand LP, respectively. AbdelGlil (1996) found high positive genetic correlations of 0.34 to 0.92 among TMY, 305-DMY, LP and DO of Friesian cattle. Hammoud (1997) obtained extremely high positive genetic correlations of 0.93 to 0.98 among TMY, 305-DMY, LP and DO of Friesian cattle. Also, El-shalmani (2011) depicted high positive genetic correlations of 0.23 to 0.98 among TMY, LP, AFC and DO of Friesian cattle. Zink et al. (2012) reported genetic correlation of 0.39 betweenTMY and DO. Goshu et al. (2014) reported positive genetic correlations of $0.79,0.32$ and 0.23 between TMY with 305-DMY, LP and AFC, respectively, but reported negative genetic correlations of $-0.69,-0.87$ and -0.15 between FSP with TMY, 305-DMY and AFC, respectively of Holstein cows in Ethiopia.

Table 3. Variance components, heritability $\left(h^{2}\right)$ and standard error $( \pm$ SE) for the studied traits

\begin{tabular}{llllll}
\hline Traits & No. & $\sigma_{\mathbf{a}}^{2}$ & $\sigma_{\mathbf{e}}^{2}$ & $\sigma_{\mathbf{P}}^{2}$ & $\mathbf{h}^{\mathbf{2}}(\mathbf{S E})$ \\
\hline TMY & 669 & 13941.5 & 49640.5 & 63582.0 & $0.219(0.082)$ \\
305-DMY & 732 & 6612.2 & 22417.8 & 29029.9 & $0.228(0.074)$ \\
PY & 725 & 4.7 & 26.1 & 30.7 & $0.150(0.071)$ \\
LP & 682 & 928.8 & 9093.2 & 10022.0 & $0.093(0.070)$ \\
AFC & 732 & 1.2 & 3.4 & 4.6 & $0.264(0.078)$ \\
FSP & 578 & 141.2 & 1405.91 & 1547.1 & $0.091(0.070)$ \\
DO & 407 & 365.9 & 1603.4 & 1969.31 & $0.186(0.108)$ \\
NSC & 605 & 0.0001 & 1.3 & 1.3 & $0.00001(0.054)$ \\
\hline
\end{tabular}

TMY: total milk yield, 305-DMY: 305-day milk yield, PY: peak yield, LP: lactation period,

AFC: age at first calving, FSP: first service period, DO: days open and NSC: number of services per conception.

$\sigma_{\mathrm{a}}^{2}$ : Additive variance, $\sigma_{\mathrm{e}}^{2}$ : residual variance, and $\sigma_{\mathrm{P}}^{2}$ : phenotypic variance.

Table 4. Genetic (below diagonal) and phenotypic correlations (above diagonal) and standard errors(S.E) among the studied traits

\begin{tabular}{|c|c|c|c|c|c|c|c|c|}
\hline Traits & TMY & 305-DMY & PY & LP & $\mathrm{AFC}$ & FSP & $\mathrm{DO}$ & $\mathrm{NSC}$ \\
\hline \multirow[t]{2}{*}{ TMY } & & $0.733^{* *}$ & $0.367^{* *}$ & $0.842^{* * *}$ & $0.101^{* *}$ & $0.497^{* * *}$ & $0.759^{* * *}$ & $0.492^{* *}$ \\
\hline & & $(0.019)$ & $(0.036)$ & $(0.012)$ & $(0.043)$ & $(0.032)$ & $(0.018)$ & $0.031)$ \\
\hline \multirow[t]{2}{*}{ 305-DMY } & $0.883^{* *}$ & & $0.571^{* * *}$ & $0.362^{* *}$ & $0.157^{* *}$ & $0.154^{* *}$ & $0.257^{* *}$ & $0.998^{* *}$ \\
\hline & $(0.150)$ & & $(0.028)$ & $(0.036)$ & $(0.041)$ & $(0.041)$ & $(0.039)$ & (0.001) \\
\hline \multirow[t]{2}{*}{ PY } & $0.488^{* *}$ & $0.968^{* *}$ & & $0.102^{* *}$ & $0.068^{\mathrm{NS}}$ & $0.024^{\mathrm{NS}}$ & $0.084^{\mathrm{NS}}$ & $0.062^{\mathrm{NS}}$ \\
\hline & $(0.308)$ & $(0.212)$ & & $(0.041)$ & $(0.043)$ & $(0.043)$ & $(0.041)$ & $(0.042)$ \\
\hline \multirow[t]{2}{*}{ LP } & $0.992^{* *}$ & $0.815^{\text {** }}$ & $0.397^{* *}$ & & $0.035^{\mathrm{NS}}$ & $0.623^{* *}$ & $0.940^{* *}$ & $0.194^{* *}$ \\
\hline & $(0.073)$ & $(0.358)$ & $(0.457)$ & & $(0.042)$ & $(0.026)$ & $(0.005)$ & $(0.038)$ \\
\hline \multirow[t]{2}{*}{ AFC } & $0.114^{* *}$ & $-0.034^{\mathrm{NS}}$ & $0.230^{* *}$ & $0.461^{* *}$ & & $0.015^{\mathrm{NS}}$ & $0.034^{\mathrm{NS}}$ & $0.010^{\mathrm{NS}}$ \\
\hline & $(0.289)$ & $(0.357)$ & $(0.292)$ & $(0.331)$ & & $(0.044)$ & $(0.042)$ & $(0.042)$ \\
\hline \multirow[t]{2}{*}{ FSP } & $0.478^{* *}$ & $0.212^{* *}$ & $-0.260^{* *}$ & $0.732^{* *}$ & $0.308^{* *}$ & & $0.687^{* *}$ & $-0.172^{*}$ \\
\hline & $(0.255)$ & $(0.390)$ & $(0.347)$ & $(0.214)$ & $(0.236)$ & & $(0.022)$ & $(0.041)$ \\
\hline \multirow[t]{2}{*}{ DO } & $0.977^{* *}$ & $0.999^{* *}$ & $0.524^{* *}$ & $0.870^{\text {*** }}$ & $0.604^{* *}$ & $0.910^{* * *}$ & & $0.577^{\text {** }}$ \\
\hline & $(0.159)$ & $(0.482)$ & $(0.083)$ & $(0.136)$ & $(0.345)$ & $(0.152)$ & & $(0.028)$ \\
\hline \multirow[t]{2}{*}{ NSC } & $0.699^{* *}$ & $0.997^{* *}$ & $0.995^{* *}$ & $0.171^{* *}$ & $0.656^{* *}$ & $-0.761^{* * *}$ & $-0.086^{\mathrm{NS}}$ & \\
\hline & $(0.445)$ & $(0.001)$ & $(0.523)$ & $(0.416)$ & $(0.997)$ & $(0.221)$ & $(0.639)$ & \\
\hline
\end{tabular}

TMY: total milk yield, 305-DMY: 305-day milk yield, PY: peak yield, LP: lactation period, AFC: age at first calving, FSP: first service period, DO: days open and NSC: number of Services per conception. NS: Not significant $(\mathrm{P}>0.05)$; **: Highly significant $(\mathrm{P}<0.01)$

\section{C- Phenotypic correlation:}

Table (4) indicates that Phenotypic correlations among the studied traits were positive ranging from
0.010 to 0.998 except that between FSP and NSC which was negative (-0.172).Most of correlations were highly significant. Abdel-Glil (1996) found 
positive phenotypic correlations of $0.87,0.71,0.05$, $0.25,0.52,0.06,0.12,0.01$ and 0.40 between TMY with 305-DM, LP, AFC, and DO, between 305-DM with LP, AFC, and DO and between LP with AFC and DO, respectively. Hammoud (1997) found positive phenotypic correlations of $0.89,0.20,0.460 .290 .20$ and 0.72between TMY with 305-DMY, AFC and DO, between305-DMY with AFC and DO and between LP and DO, respectively but, found negative phenotypic correlations of $-0.75,-0.03,-0.46,-0.13$ between TMY with LP and AFC, between 305-DMY with LP and between AFC and DO, respectively. Also, El-shalmani (2011) depicted positive genetic correlations of 0.23 to 0.98 among TMY, LP, AFC and DO of Friesian cattle. Goshu et al. (2014) depicted positive phenotypic correlations of $0.90,0.55,0.06,0.23$ and 016between TMY with 305-DMY, LP and AFC, between 305DMY with LP and between LP with FSP, respectively, but depicted negative phenotypic correlations of -0.11 and -0.23 between FSP with TMY and 305-DMY, respectively.

\section{CONCLUSIONS}

Moderate heritability estimates for TMY, 305DMY and PY indicated the need for designing an effective breeding program to improve the first lactation milk yield traits through selection. The significant genetic correlation of 0.968 and 0.488 between PY with 305-DMY and TMY indicated that selection for high PY will result in correlated response to genetic improvement in both 305-DMY and TMY.

\section{ACKNOWLEDGMENT}

The authors are grateful to Mr. Khaled AbdelAziz Amin, the dairy specialist of the Project for his kind help and cooperation in data collection.

\section{REFERENCES}

Abdel-Glil, M.F., 1996. Estimation of genetic parameters and trends for some milk traits in a herd of Friesian cows in Egypt. J. Agric. Mansoura Univ. 21: 3479.

Abou-Bakr, S., H.O.A. Alhammad, R.R. Sadek and A.A. Nigm, 2006. Productive and reproductive characteristics of Holstein cows raised under intensive farming system in Egypt. Egypt. J. Anim. Prod. 43: 91.

Abou-Bakr, S., U.M. El-Saied and M.A.M. Ibrahimm, 2000. Genetic and phenotypic parameters for milk yield, days open and number of services per conception of Holstein cows of a commercial herd in Egypt. Egypt. J. Anim. Prod. 37: 9.

Ahmad, M.J.H., J. Van Der Werf and K. Javed, 2001. Genetic and phenotypic correlation for some economic traits in dairy cattle. Pakistan Vet. J. 21: 81 .

Dematawewa, C.M.B. and P.J. Berger, 1998. Genetic and phenotypic parameters for 305-day yield, fertility and survival in Holsteins. J. Dairy Sci. 81: 2700 .

El-shalmani, A.F., 2011. Evaluation of production performance in relation to genetic structure of some economical traits in Friesian cows. Ph.D. Thesis, Fac. of Agric. Saba Basha, Alex. Univ., Egypt.

FAO, 2010. FAOSTAT Database Results, http: // www.fao.org.

Galal, S., 2007. Farm animal genetic resources in Egypt. Egypt. J. Anim. Prod. 44: 1.

Goshu, G.,H. Singh,K. Petersson and N. Lundeheim, 2014. Heritability and correlation among first lactation traits in Holstein cows at Holeta Bull Dam Station, Ethiopia. Int. J. Livest. Prod. 5: 47.

Hammoud, M.H., 1997. Selection indexes for genetic improvement of some economic traits in Friesian cattle in Egypt. Ph. D. Thesis, Fac. Agric., Alex. Univ., Egypt.

Javed, K.,M. Abdullah, M. Akhtar and M. Afzal, 2001. Phenotypic and genetic correlation between first lactation milk yield and some performance traits in Sahiwal cattle. Pakistan Vet. J. 24: 9.

Khattab, A.S. and Z.A. Sultan, 1990. Estimates of phenotypic and genetic parameters for first lactation performance in Friesian cattle in Egypt. Egypt. J. Anim. Prod. 27: 147.

Meyer, K., 2006. WOMBAT - Digging deep for quantitative genetic analyses by restricted maximum likelihood. Proc. $8^{\text {th }}$ World Congress of Genetics Applied for Livestock. 8 Production, Communication No. 27-14.

Nigm, A.A., M.B. Aboul-Ela, R.R. Sadek and M.A. M. Ibrahim ,1994. Milk production characteristics in the first two lactations of Friesian cattle in the United Arab Emirates. Egypt. J. Anim. Prod., 31: 235.

NRC, 1989. Nutrient requirements of dairy cattle. $6^{\text {th }}$ edition. National Academy of Science, National Research Council. Washington, D.C.USA.

Pantelic, V.,L. Sretenovic, D. Ostojic-Andric, S. Trivunovic, M.M. Petrovic, S. Aleksic and D. Ruzic-Muslic, 2011. Heritability and genetic correlation of production and reproduction traits of Simmental cows. African. J. Biotechnol. 10: 7117.

Rahman, M., R. Islam, M.M. Rahman, M. Haque and T. Das, 2007. Estimation of genetic parameters for economic traits in dairy cattle of Bangladesh. Asian J. Anim. Vet. Advances. 2: 9.

Rehman, Z.U., M.S. Khan, S.A. Bhatti, J. Iqbaland A. Iqbal, 2008. Factors affecting first lactation performance of Sahiwal cattle in Pakistan. Arch. Tierz. Dunmerstorf, 51: 305.

Sadek, R.R., E.A. Helali, M.A. Safwat, S.A.M. Ibrahimand A. Abd El-fatah, 1994. Evaluation of Friesian cattle performance in commercial farms in Egypt. Egypt. J. Anim. Prod. 31: 43.

Sahin, A., Z.Ulutas, A.Y. Adkinson and R.W. Adkinson, 2014. Genetic parameters of first 
lactation milk yield and fertility traits in Brown Swiss cattle. Annals Anim. Sci. 14: 545.

Salem, M.A., H.M. Esmail, R.R. Sadek and A.A. Nigm, 2006. Phenotypic and genetic parameters of milk production and reproductive performance of Holstein cattle under the intensive production system in Egypt. Egypt.J. Anim. Prod. 43: 1.

SAS, 2008. Statistics Analysis System user's Guide, (Release 9.2). SAS Institute Inc., Cary, North Carolina, USA.

Tekerli, M. and S. Kocak, 2009. Relationships between production and fertility traits in first lactation and lifetime performances of Holstein cows under subtropical conditions. Archiv Tierzucht, 52: 364 .
Tiezzi, F.,C. Maltecca,A.Cecchinato, M.Penasa and G. Bittante , 2012.Genetic parameters for fertility of dairy heifers and cows at different paritiesand relationships with production traits in first lactation. J. Dairy Sci. 95: 7355.

Tozer, P.R. and A.J. Heinrich, 2001. What affects the costs of raising replacements dairy heifers: a multiple-complement analysis. J. dairy Sci., 84: 1836.

Zink, V., J. Lassen and M. Stipkova, 2012. Genetic parameters for female fertility and milk production in first-parity Czech Holstein cows. Czech. J. Anim. Sci., 57: 108.

\title{
المعايير الوراثية لصفات موسم الحليب الأول لأبقار الهولشتين في مصر
}

\author{
محمد محمود سالم، محمد حسن حمود \\ قسم الإنتاج الحبيوانس، كلية الزراعة، جامعة الإسكندرية
}

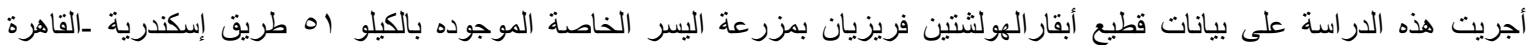

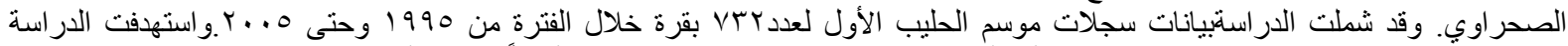

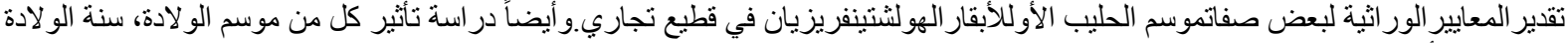

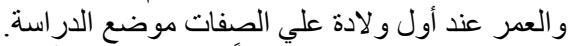

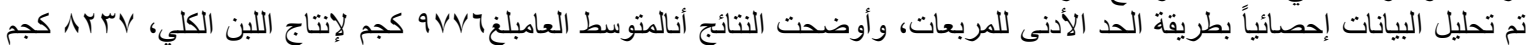

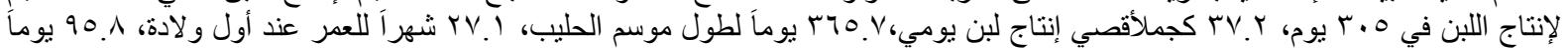

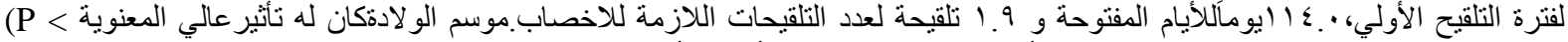

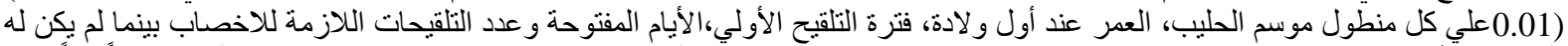
تأثبر معنوياً)

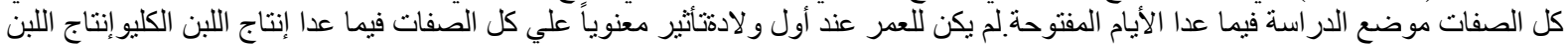

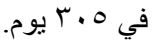

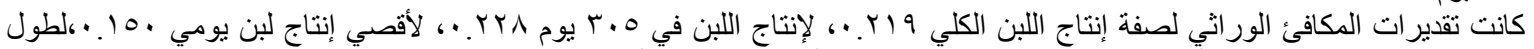

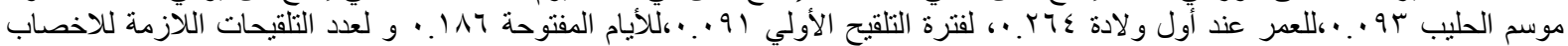

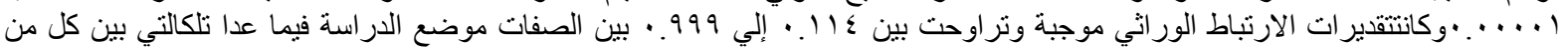

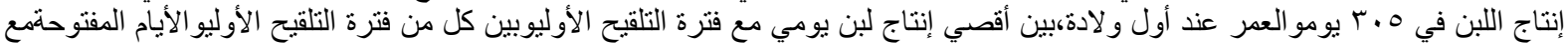

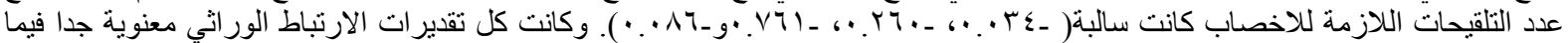

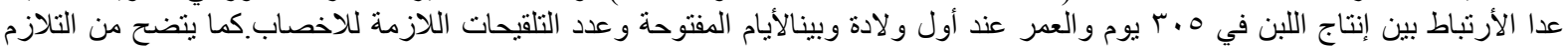

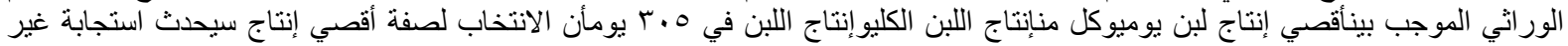

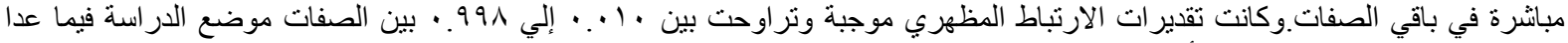

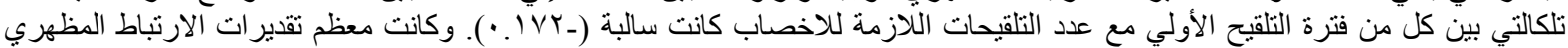

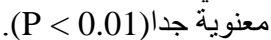

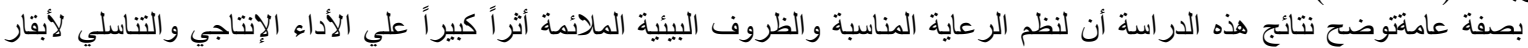

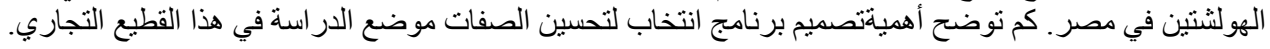

